\title{
Highly selective synthesis of citronellal in water at multigram scale by Pd nanoparticles-catalyzed hydrogenation of citral
}

\author{
Marion Duval, ${ }^{a, b}$ Gilles Sagorin, ${ }^{b}$ Audrey Denicourt-Nowicki, ${ }^{* a}$ and Alain Roucoux, ${ }^{* a}$
}

The synthesis of citronellal, an added-value chemical for perfumery, was carried out by selective and green hydrogenation of citral into citronellal in water. Aqueous suspensions of spherical ammonium-capped palladium nanoparticles with sizes around 3nm selectively reduced the conjugated carbon-carbon double bond. An excellent selectivity of $95 \%$ in citronellal was achieved at complete conversion under mild reaction conditions on a realistic $2 \mathrm{~g}$ scale in water. The presence of potassium hydroxide proved crucial to control the selectivity and avoid other hydrogenation co-products. These optimized results were further extended to a $135 \mathrm{~g}$ substrate loading with a relevant turnover number (TON) of 10000.

\section{Introduction}

Citronellal represents a high added-value product used as a food flavor additive for its lemongrass-like odor, ${ }^{1}$ or as a key synthon for the production of menthol or hydroxydihydrocitronellal. ${ }^{2}$ This relevant molecule could be produced by the selective hydrogenation of the carbon-carbon double bond of citral, a highly available synthon. ${ }^{3}$ Owing to the presence of three unsaturations, namely a $\alpha, \beta$-unsaturated aldehyde and an additional isolated carbon-carbon double bond, the competitive or successive hydrogenation processes could lead to the formation of various co-products, such as nerol or geraniol according to the stereochemistry of the double bond, or dihydrocitronellal (Figure 1), ${ }^{4}$ as well as isomerization or cyclization products. The efficient control of the selectivity remains challenging and crucial in regards to the difficult separation of the various products that could be formed, as well as the alteration of the odor quality due to the presence of impurities even at very low amounts. ${ }^{5}$ According to the metal, distinct reaction pathways are favored, affording various hydrogenation products. ${ }^{6}$ Unsaturated alcohols are generally obtained with gold, ruthenium or rhodium catalysts through the reduction of the carbonyl group, while palladium catalysts remain highly selective toward the carbon-carbon double bond. ${ }^{7-8}$ Thus, many heterogeneous palladium catalysts have been applied to the hydrogenation of citral into citronellal with selectivities up to $90 \%,{ }^{9-13}$ but require a good control of the reaction to avoid the formation of dihydrocitronellal and 3.7-dimethyloctan1-ol at higher conversions. One of the industrial processes is catalyzed by a palladium on carbon, in methanol with triethylamine, with a citronellal yield around $90 \% .{ }^{14}$ More recently, in the drive towards economic and sustainable chemical processes, ${ }^{15}$ the design of stable, low cost and highly efficient catalysts for the hydrogenation of citral in green solvents has attracted great interest. In that context, some palladium-nanoparticles based catalysts in ecoresponsible solvents, such as polyethyleneglycol (PEG), ${ }^{16}$ supercritical carbon dioxide ${ }^{17}$ or $\mathrm{CO}_{2}$-in-water-emulsion, ${ }^{18}$ have been used, but with selectivities inferior to $80 \%$. To our knowledge, there is only one example of a complex catalytic system, composed of phosphino-modified polymer immobilized ionic liquid stabilized Pd nanoparticles described for the aqueous phase chemoselective hydrogenation of citral. ${ }^{19}$ In this paper, we describe the use of palladium nanoparticles, capped with either ammonium salts or polymer, in neat water for the selective hydrogenation of citral into citronellal and the successful scale-up of the biphasic substratewater process on a multigram scale in a collaborative work with the "Dérivés Résiniques et Terpéniques" (DRT) company (Castets, France).

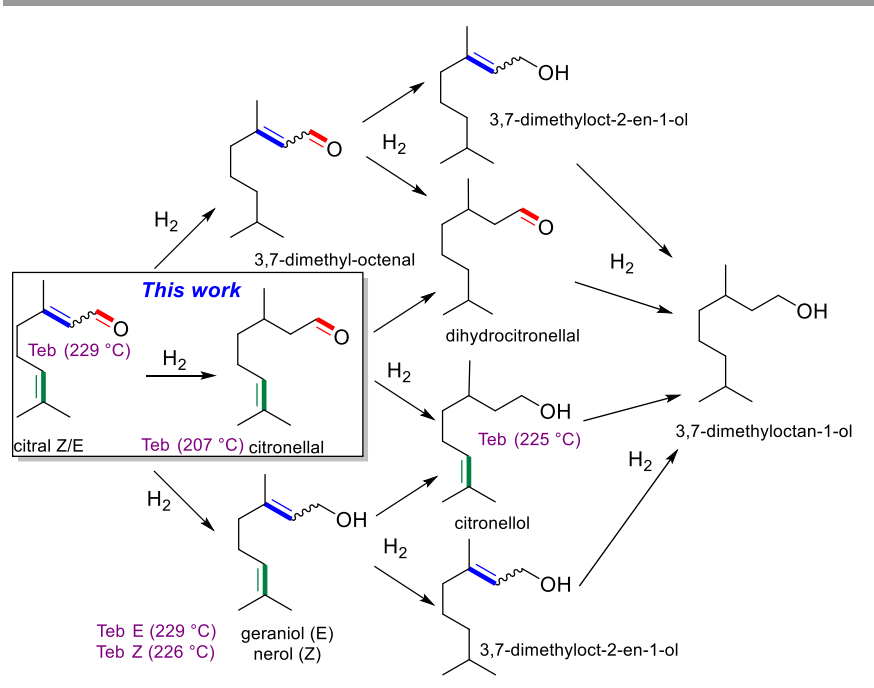

Figure 1. The competitive citral hydrogenation pathways.

\section{Experimental}

\section{Starting Materials}

Sodium tetrachloropalladate $\mathrm{Na}_{2} \mathrm{PdCl}_{4} \bullet 6 \mathrm{H}_{2} \mathrm{O}$ was purchased from Strem Chemicals. Citral (96 \%, 60:40 E/Z) and additives were obtained from Sigma or Acros Organics. All surfactants and polymers were commercial, except for $N, N$-dimethyl- $N$-cetyl- $N$-(2hydroxyethyl) ammonium chloride ( $\mathrm{HEA} 16 \mathrm{Cl}$ ) which was synthesized according to a procedure already reported by the laboratory. ${ }^{20}$ Water was distilled twice before use.

\section{Equipments}

Pressure reactions. For catalytic tests at lab-scale, stainless steel pressure reactor was from Parr Instrument Company (maximal pressure $(\mathrm{PS})=200$ bar, maximal temperature $(\mathrm{TS})=-15^{\circ} \mathrm{C}-350^{\circ} \mathrm{C}$, internal diameter $(\mathrm{Di})=3.3 \mathrm{~cm}$, height $(\mathrm{h})=5.5 \mathrm{~cm})$ equipped with a glass cell $(\mathrm{V}=50 \mathrm{~mL})$, a magnetic stirring and a heating plate. For 
experiments on a larger scale (Figure 2), a pressure reactor $(1 \mathrm{~L})$ from Top Industrie, equipped with a hollow shaft mechanical stirrer was used (maximal pressure (PS) $=310$ bar, maximal temperature $(\mathrm{TS})=10^{\circ} \mathrm{C}-250^{\circ} \mathrm{C}$, internal diameter $=10.7 \mathrm{~cm}$, height $=22.5 \mathrm{~cm}$ ).
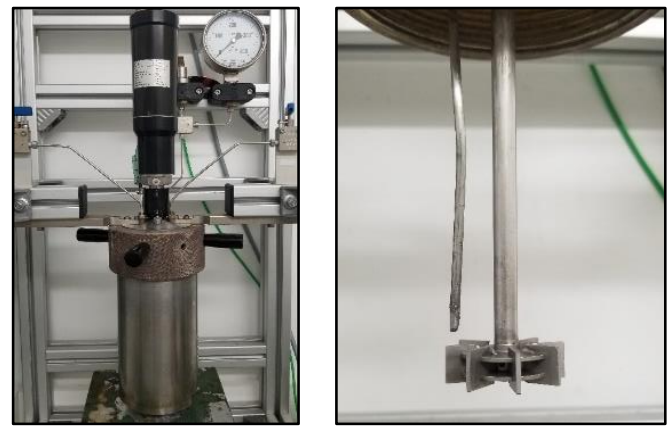

Figure 1. Pressure reactor for large-scale hydrogenation $(1 \mathrm{~L})$ with a hollow shaft mechanical stirrer

Static multiple light scattering - Turbiscan technology. Static multiple light scattering analyses were performed with the Turbiscan Lab technology (Formulaction, Toulouse, France). This apparatus is constituted of a near infrared light source (wavelength $1 / 4880 \mathrm{~nm}$ ), and two synchronized detectors, which all move vertically alongside the cylindrical glass sample cell. The light source head scans the entire sample height (up to $55 \mathrm{~mm}$ ), and the detectors acquire transmission and backscattering data every $40 \mu \mathrm{m}$. The measured photon fluxes are calibrated with a non-absorbing scattering standard (calibrated polystyrene latex beads) and a transmittance standard (silicon oil). The temperature of the apparatus was regulated at $25.0 \pm 0.1{ }^{\circ} \mathrm{C}$. The aqueous suspensions were studied without any dilution and scanned every $4 \mathrm{~h}$, along 7 days.

Dynamic light scattering experiments. The dynamic light scattering (DLS) experiments were carried out using a DelsaNano C instrument (Beckman Coulter). The prepared aqueous suspensions of $\mathrm{Pd}(0)$ NPs were analysed without any dilution at $25^{\circ} \mathrm{C}$, after the temperature equilibration, about $10 \mathrm{~min}$ after the cell was placed in the DLS apparatus.

TEM experiments. Transmission electron microscopy (TEM) images were recorded with a JEOL TEM 100CXII electron microscope operated at an acceleration voltage of $100 \mathrm{kV}$, with a KeenView camera and the ITEM software $(1376 \times 1032 \mathrm{px})$. The samples were prepared by addition of a drop of the colloidal suspension on a copper grid coated with a porous carbon film.

GC-FID analysis. Gas chromatography was performed using a Trace GC Ultra (Thermo Scientific) apparatus with a FID detector, equipped with a Thermo Fisher HP5-MS apolar capillary column (5\%-Phenylmethylpolysiloxane; $30 \mathrm{~m}, 0.25$ i.d., 0.5 f.t.). Parameters were as follows: temperature was increased from 120 to $140{ }^{\circ} \mathrm{C}$ at $2{ }^{\circ} \mathrm{C} / \mathrm{min}$, maintained at $140^{\circ} \mathrm{C}$ for $2 \mathrm{~min}$, further increased to $230^{\circ} \mathrm{C}$ with a ramp of $5^{\circ} \mathrm{C} / \mathrm{min}$ and maintained $10 \mathrm{~min}$, injector temperature $200{ }^{\circ} \mathrm{C}$, detector temperature $250^{\circ} \mathrm{C}$, injection volume $1 \mu \mathrm{L}$, split flow $16 \mathrm{~mL} / \mathrm{min}$, carrier gas (He) $0.8 \mathrm{~mL} / \mathrm{min}$. Chromatograms were treated with ChromQuest software. Products identification was performed by comparison of their retention times with commercial products. Reaction rate and selectivity were determined by standard calibration with $n$-dodecane as internal standard.

\section{Preparation of catalytic suspensions}

To an aqueous solution $(5 \mathrm{~mL}$ ) of a chosen stabilizing agent (2 equiv., $7.6 \times 10^{-5} \mathrm{~mol}$ ) was added $1 \mathrm{~mL}$ an aqueous solution of sodium borohydride ( 2.5 equiv., $9.5 \times 10^{-5} \mathrm{~mol}$ ). Then, this solution was quickly added under vigorous stirring to an aqueous solution $(4 \mathrm{~mL})$ of the metallic precursor ( 1 equiv., $3.8 \times 10^{-5} \mathrm{~mol}$ ) to obtain a colloidal suspension of $\operatorname{Pd}(0)$ nanoparticles. The reduction occurred instantaneously and was manifested by a color change. The suspension was kept under stirring $12 \mathrm{~h}$ before use.

\section{Hydrogenation reactions}

In a typical experiment, the aqueous suspension of Pd nanoparticles $(0.0076 \mathrm{~mol} / \mathrm{L}$ of $\mathrm{Pd}$ in water) and the appropriate amount of citral were introduced in the reactor. Additives could be added in small amount (3.5 equiv./metal or 5 equiv./metal). The autoclave was sealed and purged with $\mathrm{H}_{2}$ and pressurized to the given pressure. The reaction was kept at room temperature, under stirring during the desired reaction time. At the end of the reaction, the reaction products were extracted with diethyl ether $(3 \times 10 \mathrm{~mL})$ and analyzed by GC-FID and purified by silica gel column chromatography using diethyl ether/pentane (5:95) mixture as an eluent.

\section{Results and discussion}

In a first set of experiments, aqueous suspensions of palladium nanoparticles were synthesized by chemical reduction of sodium tetrachloropalladate $\left(\mathrm{Na}_{2} \mathrm{PdCl}_{4} \bullet 6 \mathrm{H}_{2} \mathrm{O}\right)$, in the presence of different capping agents such as polyvinylpyrrolidone (PVP) or cetyltrimethyl ammonium chloride (CTACl), both commercially available, as well as the easily synthesized $\mathrm{N}, \mathrm{N}$-dimethyl- $\mathrm{N}$-cetyl- $\mathrm{N}$-(2-hydroxyethyl) ammonium chloride $(\mathrm{HEA} 16 \mathrm{Cl}){ }^{21}$ These systems have been evaluated as catalysts for the selective hydrogenation of citral, at room temperature $\left(25^{\circ} \mathrm{C}\right)$ and 5 bar of dihydrogen (Figure 3$)$. In all cases, citronellal was observed by Gas Chromatography as major product, with dihydrocitronellal as co-product. Best reaction kinetics were achieved with the commercial CTACl and PVP, with conversions up to $90 \%$ in $2.5 \mathrm{~h}$ and $1.7 \mathrm{~h}$ respectively. 


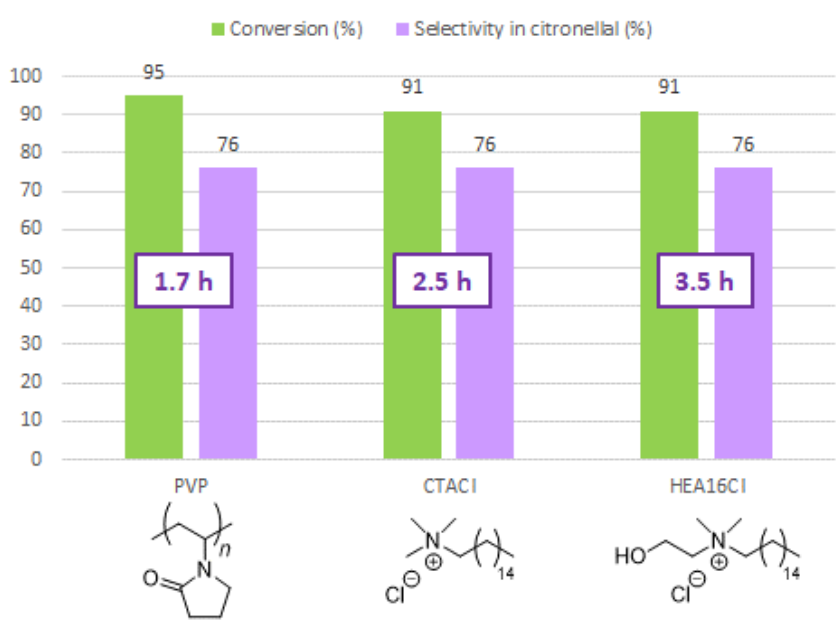

Figure 3. Comparison of three capping agents of the Pd NPs. Reaction conditions: citral $\left(12.6 \times 10^{-3} \mathrm{~mol}, \quad 1\right.$ equiv. $)$, metal $\left(0.076 \times 10^{-3} \mathrm{~mol}, 0,006\right.$ equiv. $), \quad \mathrm{HEA} 16 \mathrm{Cl}$ ( $0.15 \times 10^{-3} \mathrm{~mol} ; 0,012$ equiv.), $\mathrm{H}_{2} \mathrm{O}(10 \mathrm{~mL})$, ratio substrate/metal (166), 5 bar $\mathrm{H}_{2}, 25^{\circ} \mathrm{C}$.

The influence of the $\mathrm{pH}$ values has been investigated, since bases such as triethylamine or sodium hydroxide are used in the current industrial processes. Moreover, several studies in the literature have showed the positive impact of alkaline additives to control the selectivity to citronellal. ${ }^{19,} 22-23$ Thus, the addition of sodium hydroxide ( $\mathrm{NaOH}$ ) with various ratios (from 2.3 to 5.0 equiv./ metal) was performed on the hydrogenation of citral in the presence of PVPor CTACl-capped $\mathrm{Pd}$ nanoparticles, under 5 bar $\mathrm{H}_{2}$ and at room temperature (Table 1). In the case of PVP@Pd catalyst, no significant improvement of the selectivity was observed with $\mathrm{NaOH}$ (Entries 1 vs. 2). However, with the CTACI@Pd catalytic system, the reaction kinetics was increased (Entries 5-7), with complete conversion in 1.6 to $2.5 \mathrm{~h}$ according to the $\mathrm{pH}$ value increasing and the ratio of base added. Moreover, the selectivity in citronellal was significatively improved at complete conversion, reaching a $95 \%$ value (Entry 7) with 5 equiv./metal of $\mathrm{NaOH}$. The formation of dihydrocitronellal B is slowed down under basic conditions, allowing a better control of the selectivity in citronellal thanks to the presence of a plateau superior to $95 \%$ (See Supporting Information, Figure S1). For comparison, in the presence of chlorhydric acid providing a $\mathrm{pH}$ value of 2 (Entry 4), the citronellal A was quickly transformed into dihydrocitronellal B (34\%) and menthoglycol D (35\%), thus achieving a poor selectivity of $26 \%$ in citronellal. Due to the clear impact of the base on catalytic performances, a screening of some organic (Table 2, Entries 2-3) and inorganic bases (Table 2, Entries 4-9) has been carried out with Pd@CTACl catalyst, under 5 bar of dihydrogen and at room temperature.

Organic bases such as triethanolamine (Entry 2) and 2,2'-bipyridine (Entry 3) at 5.0 equiv./metal displayed poor conversions compared to the standard Pd@CTACl system (Entry 1) or mineral bases (Entries 4-9). In a first approach, this phenomenon could be explained by the coordination of these compounds as ligands on the particle surface, thus limiting the substrate's access. Among the mineral bases added with a 5 equiv./metal ratio, weak ones (Entries 4-5), such as sodium hydrogen carbonate $\left(\mathrm{NaHCO}_{3}\right)$ or sodium carbonate $\left(\mathrm{Na}_{2} \mathrm{CO}_{3}\right)$, afforded lower selectivity than sodium hydroxide ( $80 \%$ vs $95 \%$ at same conversion value). On the contrary, stronger bases like lithium hydroxide LiOH (Entry 6) or potassium hydroxide $\mathrm{KOH}$ (entry 8) led to excellent selectivity of $93 \%$ and $97 \%$. We could presume that the presence of $\mathrm{K}^{+}$and $\mathrm{OH}^{-}$ions modifies the electronic environment at the particle surface and consequently the active catalytic sites, thus favoring the reduction of the conjugated double bond compared to the isolated one.

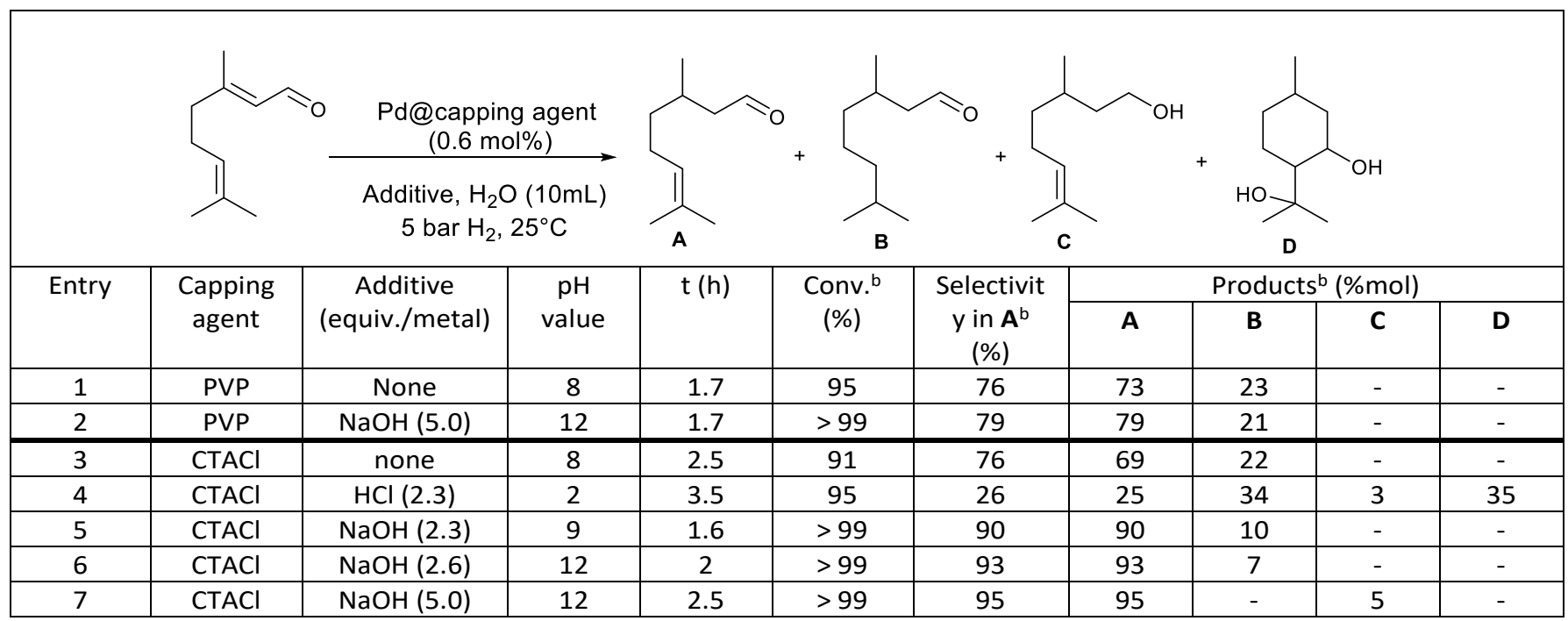

a Reaction conditions : citral (1.92 g, $12.6 \times 10^{-3} \mathrm{~mol}, 1$ equiv.), $\mathrm{Pd}\left(0.076 \times 10^{-3} \mathrm{~mol}, 0.006\right.$ equiv.), stabilizer $\left(0.15 \times 10^{-3} \mathrm{~mol} ; 0.012 \mathrm{equiv}\right.$ ), $\mathrm{H}_{2} \mathrm{O}(10 \mathrm{~mL}), \mathrm{ratio}$ substrate/metal (166), 5 bar $\mathrm{H}_{2}, 25^{\circ} \mathrm{C}$. ${ }^{\text {b }}$ Determined by GC-FID. 
Table 2. Screening of various bases on the Pd@CTACl-catalyzed hydrogenation of citral ${ }^{\mathrm{a}}$

\begin{tabular}{|c|c|c|c|c|c|c|c|c|}
\hline \multirow[t]{2}{*}{ Entry } & \multirow[t]{2}{*}{ Base (equiv./metal) } & \multirow[t]{2}{*}{$\mathrm{pH}$} & \multirow[t]{2}{*}{$t(h)$} & \multirow[t]{2}{*}{ Conv. $^{\mathrm{b}}(\%)$} & \multirow[t]{2}{*}{ Selectivity in $\mathbf{A}^{\mathrm{b}}(\%)$} & \multicolumn{3}{|c|}{ Products $^{\mathrm{b}}(\% \mathrm{~mol})$} \\
\hline & & & & & & A & B & C \\
\hline 1 & none & 8 & 2.5 & 91 & 76 & 69 & 22 & - \\
\hline 2 & Triethanolamine (5.0) & 9 & 1.8 & 85 & 88 & 75 & 5 & 5 \\
\hline 3 & 2,2'-bipyridine (5.0) & 8 & 4 & 89 & 94 & 84 & 5 & - \\
\hline 4 & $\mathrm{NaHCO}_{3}(5.0)$ & 8 & 3 & $>99$ & 81 & 81 & 19 & - \\
\hline 5 & $\mathrm{Na}_{2} \mathrm{CO}_{3}(5.0)$ & 10 & 2.7 & $>99$ & 83 & 83 & 18 & - \\
\hline 6 & $\mathrm{LiOH}(5.0)$ & 12 & 2 & $>99$ & 93 & 93 & 7 & - \\
\hline 7 & $\mathrm{NaOH}(5.0)$ & 12 & 2.5 & $>99$ & 95 & 95 & - & 5 \\
\hline 8 & $\mathrm{KOH}(5.0)$ & 12 & 2 & $>99$ & 97 & 97 & 3 & - \\
\hline
\end{tabular}

a Reaction conditions : citral $\left(1.92 \mathrm{~g}, 12.6 \times 10^{-3} \mathrm{~mol}, 1\right.$ equiv. $), \mathrm{Pd}\left(0.076 \times 10^{-3} \mathrm{~mol}, 0.006\right.$ equiv.), stabilizer $\left(0.15 \times 10^{-3} \mathrm{~mol}, 0.012 \mathrm{equiv}\right.$ ), $\mathrm{H}_{2} \mathrm{O}(10 \mathrm{~mL}), \mathrm{ratio}$ substrate/metal (166), 5 bar $\mathrm{H}_{2}, 25^{\circ} \mathrm{C}$. ${ }^{\text {b }}$ Determined by GC-FID.

The Pd@CTACl nanoparticles, in the presence of potassium hydroxide, was characterized through various techniques and compared with the standard catalysts. First, Transmission Electron Microscopy (TEM) pictures revealed spherical Pd@CTACl particles with a narrow size distribution centered on $3 \mathrm{~nm}$ (Figure 4a). When stirring with 3.5 equiv./metal of potassium hydroxide during $6 \mathrm{~h}$, small regions with agglomerated particles could be observed (Figure 4c). However, in both cases, HRTEM pictures showed isolated crystalline nanoparticles of $2.0 \mathrm{~nm}$ (Figures $4 \mathrm{~b}$ and $\mathrm{d}$ ).
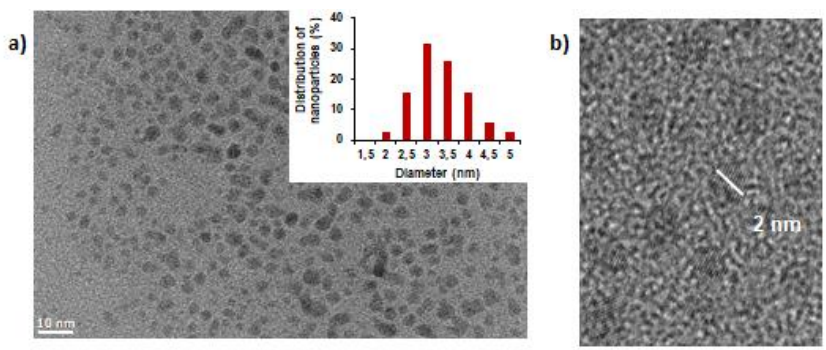

c)

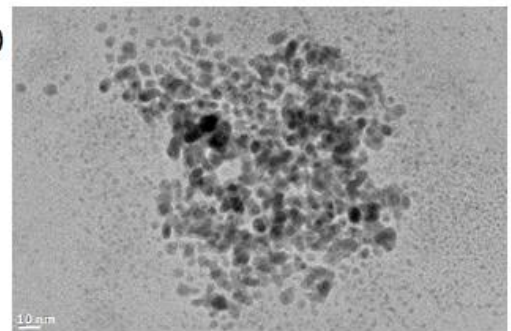

d)

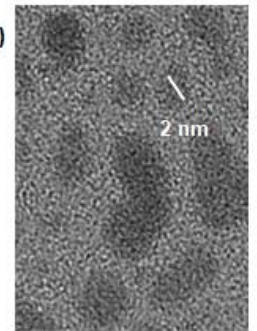

Figure 4. a) TEM (magnification $\times 200000$, scale $10 \mathrm{~nm}$ ) and size distribution of Pd@CTAC b) HRTEM of Pd@CTACl (magnification x600000), c) TEM of Pd@CTACl (+ KOH, 3.5 equiv./metal) (magnification x200000, scale 10 nm), d) HRTEM of Pd@CTACl (+ KOH, 3.5 equiv./metal) (magnification $\times 500000$ ).

Then, the dynamic light scattering technique was used to measure the hydrodynamic diameter, which increases from 33 to $38 \mathrm{~nm}$ through addition of $\mathrm{KOH}$ (3.5 equiv./metal). Thus, even at low concentration of base, the presence of $\mathrm{HO}^{-}$and $\mathrm{K}^{+}$ions close to the Stern layer and the Gouy-Chapman layer may change the size of the micellar nanoreactor and its physico-chemical properties (surface tension, hydrophilicity, etc.). ${ }^{24}$ Undoubtedly the modification of the physico-chemical interactions between the particle surface and the ions nearby may improve the adsorption of the conjugated olefinic bond over the isolated one and thus increase the selectivity to citronellal over dihydrocitronellal. ${ }^{25-26}$ This effect has already been observed in other studies by Krishna et al. ${ }^{23,27}$ The colloidal stability was also confirmed by the Turbiscan stability study of Pd@CTACl suspension (with or without $\mathrm{KOH}$ ), over 7 days (Figure 5). In both cases, TSI values inferior to 0.15 were obtained, thus ranking the suspensions in the green A+ color on the TSI scale, which is the best stability mark.
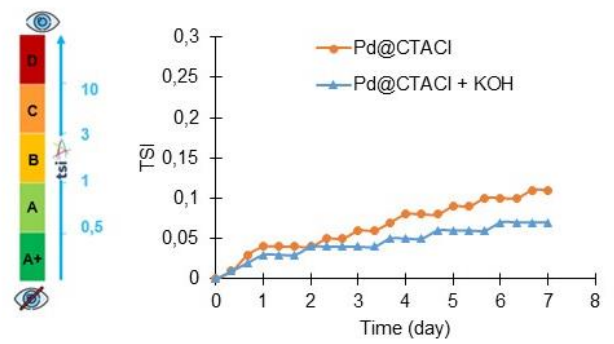

Figure 5. Turbiscan Stability Index (TSI) depending on time (day)

For economical purposes and in view of a future scale-up by DRT partner, some reactional parameters have been investigated. The amounts of water and base have been identified as potential optimizable operational parameters, in order to limit the wastewater flow. Moreover, the metal loading of this Pd@CTACl-catalyzed selective process in the presence of potassium hydroxide (3.5 equiv./metal), with a citral/Pd ratio ranging from 100 to 5000 . The results are gathered in Table 3. 
Table 3. Reaction conditions investigations for the scale-up of the Pd@CTACl-catalyzed hydrogenation of citral ${ }^{\mathrm{a}}$

\begin{tabular}{|c|c|c|c|c|c|c|c|}
\hline \multirow[b]{2}{*}{ Entry } & \multirow[b]{2}{*}{ Substrate amount (g) } & \multirow[b]{2}{*}{ Citral/ Pd } & \multicolumn{2}{|c|}{$\begin{array}{c}\mathrm{Pd} @ \mathrm{CTACl}(0.6 \mathrm{~mol} \%) \\
\mathrm{KOH}(3.5 \text { eq. }), \mathrm{H}_{2} \mathrm{O} \\
5 \text { bar } \mathrm{H}_{2}, 25^{\circ} \mathrm{C}\end{array}$} & \multirow[b]{2}{*}{ Time (h) } & \multirow[b]{2}{*}{ Conv. $^{\mathrm{b}}(\%)$} & \multirow[b]{2}{*}{$\begin{array}{c}\text { Select. in } A^{6} \\
(\% \mathrm{~mol})\end{array}$} \\
\hline & & & $\mathrm{H}_{2} \mathrm{O}$ volume $(\mathrm{mL})$ & Pressure (bar) & & & \\
\hline 1 & 1,9 & 100 & 10 & 5 & 2.5 & $>99$ & 93 \\
\hline $2^{c}$ & 5.8 & 500 & 10 & 5 & 7.2 & 93 & 93 \\
\hline 3 & 2.9 & 500 & 5 & 5 & 2 & $>99$ & 96 \\
\hline 4 & 5.8 & 1000 & 5 & 5 & 8.5 & 88 & 97 \\
\hline 5 & 5.8 & 1000 & 5 & 10 & 4.7 & $>99$ & 96 \\
\hline 6 & 5.8 & 1000 & 5 & 30 & 2 & 91 & 94 \\
\hline 7 & 17.3 & 3000 & 5 & 30 & 6.5 & $>99$ & 87 \\
\hline 8 & 28.9 & 5000 & 5 & 30 & 14.5 & 90 & 81 \\
\hline
\end{tabular}

a Reaction conditions: citral (variable), Pd@CTACl (0.0076 mol/L,5 mL), Pd (0.038 mmol), KOH (3.5 equiv./metal), 25 C. ${ }^{b}$ Determined by GC-FID. c Pd@CTACl (0.0076 $\mathrm{mol} / \mathrm{L}, 10 \mathrm{~mL})$.

In a first experiment, the amount of potassium hydroxide was decreased from 5.0 to 3.5 equiv/metal (Entry 1 ) in order to limit the ionic strength effect, while maintaining a $\mathrm{pH}$ of 12 . Under these conditions, a complete conversion was achieved in $2.5 \mathrm{~h}$, with an excellent selectivity of $93 \%$. At a constant metal concentration of 7.6 $\mathrm{mM}$, the decrease in the volume of the aqueous suspension (Entry 3) favored a better mass transfer between organic and aqueous phases, thus allowing better reaction kinetics, with a complete conversion in only $2 \mathrm{~h}$. Under these optimized conditions, promising results were obtained with a higher substrate/metal ratio of 1000 by increasing the pressure from 5 to 30 bar of dihydrogen (Entries 4-6). Thus, 91\% of the substrate was transformed with a $94 \%$ selectivity in citronellal, in 2 hours, without reducing the carbonyl function. The increase in the substrate amount from $5.8 \mathrm{~g}$ to $28.9 \mathrm{~g}$ (Entries 6-8) also leads to promising catalytic performances. However, the reaction kinetics was slower, probably due to a poor magnetic stirring efficiency with such substantial reaction volumes, thus limiting the efficient solubilization of dihydrogen within the liquid phase. Encouraging by these results, a scale-up of the process has been investigated, in a $1 \mathrm{~L}$ pressure reactor equipped with a mechanical stirrer (Figure 2), thus improving the stirring efficiency and allowing a better dihydrogen diffusion in the liquid phase emulsion. The results are gathered in Table 4. Preliminary tests were performed with a citral loading of 70 $\mathrm{g}$ and a Pd loading of $0.033 \mathrm{~mol} \%$, in the presence of $\mathrm{KOH}$, under 30 bar $\mathrm{H}_{2}$ and at $25^{\circ} \mathrm{C}$. In $2 \mathrm{~h}$, citral was completely transformed into citronellal and dihydrocitronellal in a $87 / 13$ ratio (Entry 1). The kinetics showed that after $4.5 \mathrm{~h}$, the dihydrocitronellal reached a $28 \%$ plateau (Entry 2). However, in these conditions, the reaction products were difficult to recover due to the formation of a very stable emulsion, thus requiring a liquid/liquid extraction with diethyl ether and the use of sodium chloride as an emulsion breaker. To overcome this problem, the oil/water ratio has been modified by decreasing the water volume and consequently increasing the metal concentration in the aqueous phase (from $0.076 \mathrm{~mol}^{-\mathrm{L}^{-1}}$ to 0.0127 mol. $\mathrm{L}^{-1}$ ). An increase in the oil/ $\mathrm{H}_{2} \mathrm{O}$ ratio from 4 to 6 (Entries $2 \mathrm{vs} .3$ ) allows complete conversion in 2 hours, with a significant selectivity into citronellal of $95 \%$, but did not solve the emulsion problem. A scale-up from $70 \mathrm{~g}$ to $135 \mathrm{~g}$ of citral (Entry 5), combined with an increase of the citral/Pd ratio from 3000 to 10000 leads to a complete conversion in 6 hours, with an excellent selectivity of $95 \%$.

Table 4. Scale of of the citral hydrogenation process ${ }^{\mathrm{a}}$

\begin{tabular}{|c|c|c|c|c|c|c|c|c|c|}
\hline Entry & $\begin{array}{c}\text { Citral } \\
\text { amount (g) }\end{array}$ & $\begin{array}{c}\mathrm{H}_{2} \mathrm{O} \\
\text { amount (g) }\end{array}$ & $\begin{array}{c}\text { Oil/ } \mathrm{H}_{2} \\
\text { O ratio }\end{array}$ & $\begin{array}{c}{[\mathrm{Pd}]} \\
\left(\mathrm{mol}^{-1}\right)\end{array}$ & Citral/ Pd & $\begin{array}{c}\text { Time } \\
(\mathrm{h})\end{array}$ & $\begin{array}{c}\text { Conv. } \\
(\%)\end{array}$ & $\begin{array}{c}\text { Select. in A } \\
(\% \text { mol) }\end{array}$ & $\begin{array}{c}\text { Isolated } \\
\text { Yield A (\%) }\end{array}$ \\
\hline 1 & 70 & 20 & 4 & 0.0076 & 3000 & 2 & $>99$ & 87 & 72 \\
\hline 2 & 70 & 20 & 4 & 0.0076 & 3000 & 4.5 & $>99$ & 72 & n.d \\
\hline 3 & 70 & 12 & 6 & 0.0127 & 3000 & 2 & $>99$ & 95 & 76 \\
\hline 4 & 105 & 13 & 13 & 0.0127 & 6700 & 3 & $>99$ & 92 & 79 \\
\hline 5 & 135 & 17 & 17 & 0.0127 & 10000 & 6 & $>99$ & 95 & 83 \\
\hline
\end{tabular}

a Reaction conditions: citral, Pd@CTACl, $\mathrm{KOH}$ (3.5 equiv./metal), 30 bar $\mathrm{H}_{2}, 25^{\circ} \mathrm{C}$. b Determined by GC-FID. ${ }^{\mathrm{c}}$ Isolated Yield in citronellal after distillation.

Moreover, these conditions allow to increase the oil/ $\mathrm{H}_{2} \mathrm{O}$ ratio from 6 to 17, and thus to overcome the emulsion. As an eco-friendly operation, citronellal was easily isolated by simple decantation of the product phase, followed by a distillation, to produce a $83 \%$ isolated yield into the target product. Moreover, the decrease in the water amount used in this catalytic process is promising for industrial prospects, in order to limit the wastewater flow. 
Carbon Materials for the Selective Hydrogenation of Citral Catalysts, 2013, 3, 853-877.

\section{Conclusions}

Selective hydrogenation of $\alpha, \beta$-unsaturated aldehydes constitutes a relevant transformation for fine chemistry, such as the upgrading of citral into citronellal for perfumes. The control of the selectivity at complete conversion remains a huge challenge owing to the difficult separation of the reaction products. In this paper, aqueous suspensions of $\mathrm{CTACl}$-capped palladium nanoparticles, possessing sizes around $3 \mathrm{~nm}$, showed a $95 \%$ selectivity into citronellal at complete conversion on a $2 \mathrm{~g}$-scale, under mild conditions $\left(5\right.$ bar $\mathrm{H}_{2}$, $25^{\circ} \mathrm{C}$ ). The small amount of potassium hydroxide added in the reaction media proved to be crucial to limit the formation of coproducts of hydrogenation (citronellol, dihydrocitronella) as well as isomerization (menthoglycol). These encouraging results have been successfully scaled up to $135 \mathrm{~g}$ with similar catalytic performances, with a only $0.01 \%$ metal loading and a relevant Turnover Number of 10000 . To our knowledge, this result constitutes the best reported catalytic performance for this selective reaction. These results prove the potential and pertinence of aqueous suspensions of metal nanoparticles for industrial applications in an eco-responsible context.

\section{Author Contributions}

We strongly encourage authors to include author contributions and recommend using $\underline{\mathrm{CRediT}}$ for standardised contribution descriptions. Please refer to our general author guidelines for more information about authorship.

\section{Conflicts of interest}

There are no conflicts to declare.

\section{Acknowledgements}

This research project was supported by the ANRT (PhD fellowship) and DRT company (CIFRE $n^{\circ} 2017.0109$ ). The authors are indebted to Patricia Beaunier from the Service de Microscopie Electronique at Sorbonne Universités UPMC for Transmission Electron Microscopy analyses and to the Formulaction company (Toulouse) for the static multiple light scattering analyses conducted in their laboratory with the Turbiscan equipment

\section{Notes and references}

J. B. Sharmeen, F. M. Mahomoodally, G. Zengin and F. Maggi. Essential Oils as Natural Sources of Fragrance Compounds for Cosmetics and Cosmeceuticals, Molecules, 2021, 26, 666.

2 E. J. Lenardão, G. V. Botteselle, F. de Azambuja, G. Perin and R. G. Jacob. Citronellal as key compound in organic synthesis, Tetrahedron, 2007, 63, 6671-6712.

3 E. Bailón-García, F. J. Maldonado-Hódar, A. F. PérezCadenas and F. Carrasco-Marin. Catalysts Supported on 
and R. Stones. Highly efficient aqueous phase chemoselective hydrogenation of $\alpha, \beta$-unsaturated aldehydes catalysed by phosphine-decorated polymer immobilized IL-stabilized PdNPs, Green Chem., 2017, 19, 1635-1641.

E. Guyonnet Bilé, R. Sassine, A. Denicourt-Nowicki, F. Launay and A. Roucoux. New ammonium surfactantstabilized rhodium(0) colloidal suspensions: Influence of novel counter-anions on physico-chemical and catalytic properties, Dalton Trans., 2011, 40, 6524-6531.

B. L. Albuquerque, A. Denicourt-Nowicki, C. Mériadec, J. B. Domingos and A. Roucoux. Water soluble polymersurfactant complexes-stabilized $\operatorname{Pd}(0)$ nanocatalysts: Characterization and structure-activity relationships in biphasic hydrogenation of alkenes and $\alpha, \beta$-unsaturated ketones, J. Catal., 2016, 340, 144-153.

V. Satagopan and S. B. Chandalia. Selectivity aspects in the multi-phase hydrogenation of $\alpha, \beta$-unsaturated aldehydes over supported noble metal catalysts: Part I, 1994, 59, 257263.

K.-C. Tin, N.-B. Wong, R.-X. Li, Y.-Z. Li and X.-J. Li. Studies on catalytic hydrogenation of citral by water-soluble palladium complex, J. Mol. Catal. A, 1999, 137, 113-119. T. Dwars, E. Paetzold and G. Oehme. Reactions in Micellar Systems, 2005, 44, 7174-7199. V. Ponec. On the role of promoters in hydrogenations on metals; $\alpha, \beta$-unsaturated aldehydes and ketones, Appl. Catal. A, 1997, 149, 27-48.

E. Salminen, P. Virtanen, K. Kordás and J.-P. Mikkola. Alkaline modifiers as performance boosters in citral hydrogenation over supported ionic liquid catalysts (SILCAs), Catal. Today, 2012, 196, 126-131. R. Krishna, C. Ramakrishna, K. Soni, T. Gopi, G. Swetha, B. Saini and S. Shekar. Effect of Alkali Carbonate/Bicarbonate on Citral Hydrogenation over Pd/Carbon Molecular Sieves Catalysts in Aqueous Media, Mod. Res. Catal., 2016, 1-10. G. C. Accrombessi, P. Geneste, J.-L. Olive and A. A. Pavia. Mechanism of the liquid-phase catalytic hydrogenolysis on palladium/carbon of cyclohexene epoxides, J. Org. Chem., 1980, 45, 4139-4143. 


\section{Graphical Abstract}

A multigram production of citronellal through selective hydrogenation of citral by palladium nanoparticles in water
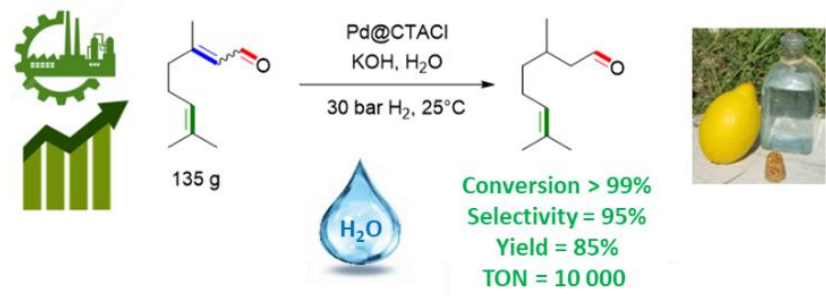